\title{
Common stress factors faced by elderly in Deoli area of Wardha district
}

\author{
Kumar Bijyendra Sourabh ${ }^{1}$, Nayak $S^{2}$, Dhande $N^{3}$, Mudey $A^{4}$, Kumari $L^{5}$, Wagh $V^{6}$ \\ ${ }^{1}$ Dr. Kumar Bijyendra Sourabh, Post Graduate Student, Department of Community Medicine, Jawaharlal Nehru Medical \\ College, Sawangi (Meghe), Wardha, Maharashtra, ${ }^{2}$ Dr Smrutiranjan Nayak, Associate Professor, Department of \\ Community Medicine, Kalinga Institute of Medical Sciences, Kushabhadra Campus (KIIT Campus-5) Patia, \\ Bhubaneswar, ${ }^{3}$ Dr. Nikhil Dhande, Assistant Professor, Department of Community Medicine, Jawaharlal Nehru Medical \\ College, Sawangi (Meghe), Wardha, Maharashtra, ${ }^{4}$ Dr. Abhay Mudey, Professor and Director, Department of \\ Community Medicine, Jawaharlal Nehru Medical College, Sawangi (Meghe), Wardha, Maharashtra, ${ }^{5}$ Dr Lovely Kumari, \\ Post Graduate Student, Department of Community Medicine, Jawaharlal Nehru Medical College, Sawangi (Meghe), \\ Wardha, Maharashtra, ${ }^{6}$ Dr. Vasant Wagh, Professor, Department of Community Medicine, Jawaharlal Nehru Medical \\ College, Sawangi (Meghe), Wardha, Maharashtra, India.
}

Address for Correspondence: Dr Smrutiranjan Nayak, Email: dr.smrutiranjannayak@gmail.com

\begin{abstract}
Background: Previous studies have shown that elderly people faced numerous socio-psychological problems like stress, declining authority, lack of respect in the family, loneliness, difference of opinion with family members. To study this we further conducted a study in the deoli area of Wardha district from June to August, 2015. Objective: To find out common stress factors faced by elderly of Deoli area in Wardha district. Methods: Observational cross-sectional study. Simple random sampling technique was followed to include the study unit in the study sample and the study unit was selected by using lottery method from among the elderly population in the deoli area. Result: Elderly are more stressed from psychosocial problems than physical problems. They mostly suffer from limitation of physical activity (78\%), back pain $(66 \%)$ and joint pain $(54 \%)$, sleep disturbance $(88 \%)$, decrease in social life $(88 \%)$, poor concentration $(76 \%)$, and financial dependency (50\%). Conclusion: It is concluded that there is urgent need for efforts on the part of the government and non-government organization to ensure guaranteed income, health care, social services, recreation and other requirements of the aged which will go a long way to reduce the problems of elderly.
\end{abstract}

Key words: stress factors, elderly people, socio-psychological problems

\section{Introduction}

Old age is generally the chronological age, a universal phenomenon and a challenge to everyone, who reaches it irrespective of occupation, skill or learning [1]. The global share of older people (aged 60 years or above) increased from 9.2 percent in 1990 to 11.7 percent in 2013 and will continue to grow as a proportion of the world population, reaching 21.1 percent by 2050 . India's population of ages 60 and older is projected to increase dramatically over the next four decade, from 8 percent in 2010 to 19 percent in 2050, according to the United Nation Population Division. The proportion of

Manuscript received $24^{\text {th }}$ May 2016

Reviewed: $5^{\text {th }}$ June 2016

Author Corrected: $20^{\text {th }}$ June 2016

Accepted for Publication $1^{\text {st }}$ July 2016 the elderly population to total population was $5.8 \%$ in 2000 and it is expected to reach $15.0 \%$ by 2050 . Rapid ageing trends present new challenges to government, families and the elderly themselves [2]. India has nearly $11.8 \%$ senior citizens in the population and has fallen in the category of a greying country.

The changes in the demographic structure during the last few decades in developing countries have made the aged a socially more noticeable section [3]. It is the old age period that people need physical, emotional and psychological support. The elderly have passed the time of creativity and flourishing and are evaluating and reviewing their life. An attempt to help them is actually 
an appreciation of their past activities and achievements.

Successful approaches to implementing change in the practices of providers emphasize moving beyond traditional models of continuing medical education to include educational techniques that actively involve the learner, as well as systems change interventions such as integrated care management, implementation toolkits, automated reminders, and decision support technologies [4].

\section{Material and Methods}

The study was carried out in Deoli area of Wardha district from June 2015 to August 2015. The objective of the study was to find out common stress factors faced by elderly. Stress factors were checked in terms of physical and psychosocial stress faced by the elderly. The study design was observational cross-sectional study. Simple random sampling technique was followed to include the study unit in the study sample and the study unit was selected by using lottery method from among the elderly population in the deoli area.

The study tool consisted of a schedule that was prepared at the department of Community Medicine. The schedule was tested initially on $10 \%$ of the sample size; the lacune were discussed and corrected as per recommendations of guides. The study was undertaken in single stage in the deoli area over a period of two months. Statistical analysis was done by using descriptive statistics and Microsoft Excel.

\section{Results}

Table-1: Socio-demographic profile of the elderly.

\begin{tabular}{|c|c|c|}
\hline Characteristics & Variables & No. Of elderly (\%) \\
\hline \multirow[t]{2}{*}{ Sex } & Male & $70(35)$ \\
\hline & Female & $130(65)$ \\
\hline \multirow[t]{5}{*}{ Age } & $60-65$ & $108(54)$ \\
\hline & $66-69$ & $20(10)$ \\
\hline & $70-75$ & $52(26)$ \\
\hline & $76-80$ & $12(6)$ \\
\hline & $>80$ & $8(4)$ \\
\hline \multirow[t]{3}{*}{ Marital status } & Married & $140(70)$ \\
\hline & Unmarried & 0 \\
\hline & Widow / Widower & $60(30)$ \\
\hline \multirow[t]{4}{*}{ Religion } & Hindu & $128(64)$ \\
\hline & Muslim & $16(8)$ \\
\hline & Buddhist & $48(24)$ \\
\hline & Others & $8(4)$ \\
\hline \multirow[t]{5}{*}{ Education } & Illiterate & $80(40)$ \\
\hline & Primary & $42(21)$ \\
\hline & Secondary & $38(19)$ \\
\hline & Higher secondary & $26(13)$ \\
\hline & Graduate & $14(7)$ \\
\hline \multirow[t]{4}{*}{ Occupation } & Unemployed & $114(57)$ \\
\hline & Labourer & $56(28)$ \\
\hline & Govt. Pensioner & $20(10)$ \\
\hline & Others & $10(5)$ \\
\hline
\end{tabular}

Table 1 shows that most of the elderly in the study was female, of age group 60-65 years, married, Hindu by religion, illiterate and unemployed. 
Table-2: Identification of common stressors faced by the elderly.

\begin{tabular}{|c|c|c|c|}
\hline Sr. No. & Stressors & Rarely & Mostly \\
\hline 1 & Physical stressors & $128(64 \%)$ & $72(36 \%)$ \\
\hline 2 & Psychosocial stressors & $84(42 \%)$ & $116(58 \%)$ \\
\hline
\end{tabular}

Table 2 shows that out of total 200 elderly, they suffered from physical and psychosocial stress. The study indicates majority of elderly (58\%) experiences psychological stress and 64\% rarely experiences physical stress.

Table-3: Identification of various items of physical stress factors in elderly.

\begin{tabular}{|c|c|c|c|}
\hline Sr. No. & Physical stressors & Rarely & Mostly \\
\hline 1 & Back pain & $68(34 \%)$ & $132(66 \%)$ \\
\hline 2 & Difficulty in chewing & $112(56 \%)$ & $88(44 \%)$ \\
\hline 3 & Difficulty in breathing & $184(92 \%)$ & $16(8 \%)$ \\
\hline 4 & Joint pain & $92(46 \%)$ & $108(54 \%)$ \\
\hline 5 & Limitation of physical activity & $44(22 \%)$ & $156(78 \%)$ \\
\hline
\end{tabular}

Table 3 shows that in the physical stress factors majority of elderly suffer from limitation of physical activity, back pain and joint pain. They also suffer from difficulty in chewing and difficulty in breathing.

Table-4: Identification of various items of psychosocial stress factors.

\begin{tabular}{|c|c|c|c|}
\hline S. No. & Psychosocial Stressors & Rarely & Mostly \\
\hline 1. & Sleep disturbance & $24(12 \%)$ & $176(88 \%)$ \\
\hline 2. & Poor concentration & $48(24 \%)$ & $176(88 \%)$ \\
\hline 3. & Decrease in social life & $24(12 \%)$ & $92(46 \%)$ \\
\hline 4. & Dependency on others & $108(54 \%)$ & $100(50 \%)$ \\
\hline 5. & Financial dependency & $100(50 \%)$ & $56(28 \%)$ \\
\hline 6. & Respect from children and grand children & $144(72 \%)$ & $6(3 \%)$ \\
\hline 7. & $\begin{array}{c}\text { Dependency of any other family members } \\
\text { on them }\end{array}$ & $194(97 \%)$ & \\
\hline
\end{tabular}

Table 4 shows that in the psychosocial stress factors majority of elderly suffer from, sleep disturbance decrease in social life, poor concentration and financial dependency. They also have problems as dependency of any other family members on them, respect from children and grand children and dependency on others.

\section{Discussion}

Nothing can remain static in this world. This is true for the human body too. Biologically speaking the aging process starts the moment we come into this world. The regulatory activity starts slowing down with age and brings about an increased vulnerability to illness and decreasing adaptability to environmental stresses and strains. India is graying and by the turn of the century there will be around 80 million Indians above the age of 60 years. Life span has increased from 32 years in 1947 to 54 years in 1980 and 62 years presently.

Stress hormones provide energy and focus in the short term, but too much stress over too many years can throw a person's system off-balance. Overloads of stress hormones have been linked to many health problems, including heart disease, high blood pressure, and weakened immune function. For older people already at heightened risk for these illnesses, managing stress is particularly important.

Forty-one professionals from various housing, psychosocial, medical, and protective service provider groups were surveyed during three consecutive rounds. The consensus achieved through the Delphi process served to describe the gaps in the mental health services currently available to elderly Harris County residents as well as identify the service needs of this population into 
the future, thereby providing direction for future service development [5].

Over time, the brain can slowly lose its skills at regulating hormone levels. As a result, older people who feel worried or anxious tend to produce larger amounts of stress hormones, and the alarm doesn't shut down as quickly.

The flow of stress hormones can be especially hard on older brains in general. According to a recent report from the University of California at San Francisco, extra cortisol over the years can damage the hippocampus, a part of the brain that's crucial for storing and retrieving memories. Several studies have found that high cortisol goes hand in hand with poor memory, so we might be able to chalk up certain "senior moments" to stress.

In a study by N. Mehrotra and S. Batish on Assessment of Problems among Elderly People of Ludhiana City indicates that elderly people faced numerous sociopsychological problems like stress, declining authority, lack of respect in the family, loneliness, difference of opinion with family members [6]. Amongst the given problems, stress and strain was experienced by maximum $(85.0 \%)$ of the respondents, while lack of participation in outside activities was encountered by minimum i.e. 25 percent of the respondents. The other problems reported were declining authority (77.50\%), lack of respect in the family $(75.0 \%)$, loneliness $(72.0 \%)$, feel neglected $(65.0 \%)$, get upset over small issues $(61.25 \%)$ and difference of opinion with family members $(47.50 \%)$.

Bakshi et al. (2007) also reported that aged persons mostly females living with families were feeling emotionally unstable [7].

Our study also supports the findings which revealed that in relation to physical problems and psychosocial problem, elderly are more stressed from psychosocial problem. They mostly suffer from limitation of physical activity (78\%), back pain (66\%) and joint pain $(54 \%)$, sleep disturbance $(88 \%)$, decrease in social life $(88 \%)$, poor concentration $(76 \%)$, and financial dependency $(50 \%)$.

They also suffer from difficulty in chewing and difficulty in breathing, dependency of any other family members on them, respect from children and grand children and dependency on others. A number of researchers have examined the relationship between age and depression, but the findings are inconsistent.

Another study found a curvilinear relationship between age and depression, showing that the youngest age groups and the oldest age group reported greater depressive symptoms than other age groups.

The good news is that we can put what we know about stress and aging to work for us. Learn to manage and reduce your stress load and you have a better chance to live a long, healthy life.

A study by Trollor, J.N et al found that women experienced higher rates of affective disorders and generalized anxiety disorder and had lower rates of substance abuse compared with men. After excluding cognitive disorder, increasing age was associated with less likelihood of having symptoms of any mental disorder. Older age and never having been married were associated with less likelihood of having symptoms of an affective disorder. Those with cognitive impairment were more likely to have had symptoms consistent with an affective disorder [8].

According to a study published in the journal Psychoneuroendocrinology, women are especially susceptible to an overload of stress hormones as they age. The study found that the impact of age on cortisol levels is nearly three times stronger for women than for men [9].

\section{Conclusion}

In the light of above findings it may be concluded that there is urgent need for efforts on the part of the government to ensure guaranteed income, health care, social services, recreation and other requirements of the aged which will go a long way to reduce the problems of elderly.

Besides this non-government organizations may also come forward for the welfare of the aged persons. Untreated or under-treated pain, anticipatory anxiety regarding the progression of medical illness, fear of dependence and burdening the family lead to suicidal ideation in elderly with medical illness. The anticipated growth in the population of older persons with mental disorders underscores the need for a strategy to facilitate the systematic and effective implementation of evidence-based practices in geriatric mental health care. 
There should be inculcation of cultural values amongst young generations, so that they understand problems of elderly and feel the responsibility for their proper care. Furthermore, worrying about old age can affect many people who are not old yet. In fact, supporting and helping the elderly can relieve people who are not old yet.

Compared to the data on pharmacological treatments, those for outcomes of psychological treatments are very limited. Existing data indicate that cognitivebehavioural, behavioural, and psychodynamic therapies are significantly better than placebo [10].

Maintaining a positive outlook is one key-- a study by Yale University found that people who feel good about themselves as they get older live about seven and a half years longer than "glass half empty" types. Researchers say the people with more positive attitudes may also deal with stress better and have a stronger will to live.

Exercise, a proven stress-buster for people of all ages, may be especially valuable in later years. Regular walks, bike rides, or water aerobics can do more than keep a person strong and independent; exercise can actually help block the effects of aging on cortisol levels.

In the end, anything that reduces unnecessary stress will make the later years more enjoyable. Some people simply need to stop trying to do too many things at once. Others may want to try breathing exercises or other relaxation techniques.

Funding: Nil, Conflict of interest: None initiated,

Permission from IRB: Yes

\section{References}

1.Tungdim MG, Kapoor S, Kapoor AK. Morphophysiological changes amongst high attitude aged. Indian J Gerontology. 2002:32-43.
2. Ramachandran R, Radhika R. Problems of elderly women in India and Japan. Indian J Gerontology.2006; 20:219-34.

3. Bhatia HS. Ageing And Society - A Sociological Study of The Retired Public Servants. Udaipur. The Arya's Book Centre Publishers. 1983;25

4. Bartel SJ, Dums AR, Oxman TE. Evidence based practices in geriatric mental health care. Psychiatry Serve. 2002; 53(11):1419-31.

5. Toward JI, Ostwald SK. Exploring mental health service needs for the elderly: results of a modified Delphi study. Community Ment Health J. 2002 Apr;38 (2):141-9.

6. Mehrotra N, Batish S. Assessment of problems among elderly people of Ludhiana City. Department of Family Resource Management, Punjab Agricultural University, Ludhiana. J Hum Ecol. 2009;28(3):213-16.

7. Bakshi R, Rajneesh, Sandhu P, Harpinder. Problems of the aged living with families and in senior citizen homes. Ageing-Strategies for an Active Old Age. 2007; $7: 61-8$.

8. Trollor JN, Anderson TM, Sachdev PS, Brodaty H, Andrews G. Prevalence of mental disorders in the elderley: The Australian National Mental Health and Well-Being Survey. Am. J. Geriatr. Psychiatry. 2007; 15:455-66.

9. Otte, C. et al. A meta-analysis of cortisol response to challenge in human aging: importance of gender. Psychoneuroendocrinology. 2005;30(1):80-91.

10. Gerson S, Belin TR, Kaufman A. Pharmacological and psychological treatments for depressed older patients: A meta-analysis and overview of recent findings. Harv. Rev. Psychiatry. 1999;7:1-28.

\section{How to cite this article?}

Kumar Bijyendra Sourabh, Nayak S, Dhande N, Mudey A, Kumari L, Wagh V. Common stress factors faced by elderly in Deoli area of Wardha district. Int J Med Res Rev 2016;4(12):2130-2134.doi:10.17511 /ijmrr. 2016.i12.09. 